\title{
Using the Roblox Video Game Engine for Creating Virtual tours and Learning about the Sculptural Heritage
}

\author{
https://doi.org/10.3991/ijet.v15i20.16535
}

Cecile Meier $\left.{ }^{(}\right)$, Jose Luis Saorín, Alejandro Bonnet de León, Alberto Guerrero Cobos

University of La Laguna, San Cristóbal de La Laguna, Spain cemeier@ull.edu.es

\begin{abstract}
This paper describes an experience to incorporate the realization of virtual routes about the sculptural heritage of a city in the classroom by developing a simulation of the urban environment using a video game engine. Video game engines not only allow the creation of video games but also the creation and navigation of interactive three-dimensional worlds. For this research, Roblox Studio has been used, a simple and intuitive program in which no previous programming skills are required. During the 2018/2019 academic year, a pilot experience was carried out with 53 secondary school students who were given the task of designing a virtual environment in which they had to include 3D models of the sculptural heritage of the city of Santa Cruz de Tenerife. Before starting the experience, the participants answered a questionnaire to obtain a previous idea of the students' knowledge about the creation of video games. Once the activity was finished and in order to evaluate the result of the activity, the participants answered a final questionnaire. The students emphasized that after the activity they were more aware of the sculptural heritage of Santa Cruz and that they considered themselves capable of creating their own interactive worlds with Roblox.
\end{abstract}

Keywords-Video game engine; Roblox; Sculptural heritage; education; threedimensional virtual world; virtual tours.

\section{Introduction}

The diffusion of the sculptural heritage of a city has an interest in promoting tourism and education. Since 1972, UNESCO [1] has been emphasizing the importance of increasing respect and appreciation of cultural heritage through education. Also, the Education, Audiovisual and Culture Executive Agency [2] determines that the understanding of cultural heritage, and therefore the sculptural heritage, must be an objective within education. The educational curriculum includes the study of contemporary culture, which contains, within the main objectives in secondary education, knowledge, appreciation and respect for artistic and cultural heritage [3]. The teaching of sculptural heritage is traditionally done through images, videos, internet or, in the best of cases, through a direct visit to the heritage of a city or to museums [4]. Because sculptures are three-dimensional objects, by disseminating them through a flat resource such as 
images, information is lost and the understanding of the works are limited [5, 6]. Of course, making direct visits is not always feasible because it involves travel, extra expenses on the part of the center and, in addition, for people with mobility difficulties it is often impossible to make this type of outing without encountering great obstacles since some sculptures are found in parks or gardens that are challenging to access.

The use of video games in the classroom to learn certain contents is already a widespread practice and is valued positively by many researchers $[7,8,9]$. However, it is not so common for students to develop video games or three-dimensional environments. In this work, the aim is for students to be the creators of their own interactive world using a video game engine, in this case Roblox Studio. A Video Game Engine is a software application that offers all the tools necessary for the programming, design and complete development of a video game $[10,11]$.

This work is a continuation of previous research [12]. In this project, Minecraft was used, as a serious video game, to recreate and navigate a virtual environment including the sculptural heritage belonging to the First International Street Sculpture Exhibition in the city of Santa Cruz de Tenerife. This environment, created by the teacher, was used with students to promote the learning of the sculptures and the results obtained were positive. In the current research, students are involved in the creation of their own virtual world. The use of video game engines is proposed with the aim of teaching students basic knowledge of video game design, encouraging their imagination and creativity, as well as widening the range of possibilities to be used to incorporate the sculptural heritage into the classroom [13]. Additionally, with this activity, it is intended that students with mobility problems can navigate through interactive environments that allow them to virtually access the city's sculptural heritage.

Together with the rise of digital games as a learning method in different areas of knowledge, the skills to create video games can be a useful tool for current secondary school students for their professional future. The annual income of the videogame market moves billions of US dollars [14] and the professional demand of the sector is increasing, so it is convenient to have adequate training profiles [15, 16]. Furthermore, early training in video game creation skills can improve the choice of future university studies [17]. Traditionally, having programming skills was one of the main needs to develop a video game $[18,19]$, however, nowadays there are alternatives that facilitate the development of video games without the need to know programming languages [20]. Roblox Studio is a program that offers the possibility of creating and sharing threedimensional virtual environments easily and has an interface suitable for children [21]. It is a multi-platform program, that is, it can be played on computers, tablets, mobiles or video consoles, thus enabling its ubiquitous access. Roblox Studio also allows the import of external 3D files, apart from those offered by the program itself.

To validate the proposal described in this work, an activity has been carried out with 53 fourth-year secondary students on the subject of plastic, visual and audiovisual education, where they were taught to create through Roblox Studio, a three-dimensional virtual world that included part of the sculptural heritage of the city of Santa Cruz de Tenerife. Surveys were carried out before and after the experiment in order to obtain an evaluation of the activity by the participants. 


\section{Background}

The first video game engine was created by the company Id Software to develop a video game called Doom in the mid-1990s [22]. To date, video games were programmed pixel by pixel using code. The creation of John Carmack, founder of the company, would then become an important precursor that would make the job easier for video game developers [23].

Currently, there are several professional video game engines, such as Shiva3D [24] which is very suitable to a 3D game design, Unreal Engine, which is among the most used and popular video game engines in the professional video game industry [25]. Another example is CryEngine, which has an online library where the community creates and shares content, some free and some paid, to be used by users easily in their projects [26]. Another alternative is Unity [27], which, with its appearance in 2005, is among the most popular game engines. The download and license of this graphic engine has always been free for educational uses; besides it is widely compatible with other video game engines and allows the incorporation of almost all file formats. On the other hand, Unreal Engine [28], has a large part of the program with a visual programming language, that is to say, it is not necessary to write a code but it works based on preprogrammed blocks. This type of block-based programming is being used a lot in education, especially to introduce children to programming.

In recent years, programming languages have appeared that are simple to use and for which no advanced knowledge is required to create video games or virtual tours. One of the first to appear was LOGO, a programming language designed to teach students how to program, allowing them to control a "turtle" that moves and draws to create graphic effects. By simplifying the language, LOGO made programming more accessible to novices and made it an effective tool in educational environments [29, 30]. Other current examples are Codebyte, which aims to teach programming in a fun way, Code.org, a program that teaches the first steps of programming. Learning to program, an initiative that works with blocks but is not free. Bitbloq, an intuitive tool oriented towards education but complex to start in programming or for example BeetleBlocks allows programming in a 3D scenario [31].

Another of the most popular programming languages today is Scratch. This program was developed by the Lifelong Kindergarten group of the MIT Media Lab at the Massachusetts Institute of Technology and was published in 2007. It is a completely free program, designed to develop only $2 \mathrm{D}$ video games. It allows creation without knowledge of code and promotes computational thinking by connecting pre-programmed blocks that can be configured by the user [32]. Stencyl is another 2D game creation tool [33], it does not require programming knowledge, and it is aimed at students of all stages, from Primary Education to University. Its even friendly interface is more professional compared to Scratch. It handles more advanced concepts, more versatility when it comes to importing and exporting files, modifying physics, events or element properties. There are many other programs such as Adventure Game Studio, Construct 3D, 3D Entity, Game Salad, Godot, etc. All of them have a simple operation and allow to create video games in a more or less easy way [34]. 
This brings us to Roblox (Fig. 1) which was developed by Roblox Corporation in 2003, being published after several Beta versions in 2006 [35]. Roblox can be used on all major platforms: Windows, OS X, Linux, iOS, Android, PlayStation and Xbox. It is completely free and allows users to create or play $3 \mathrm{D}$ games, as well as to share it online with the community. In its catalogue it has a great variety of genres such as adventure, shooter, terror, etc. It also has a paid part to get extras, and even allows anyone to earn money if their creations become popular [36].

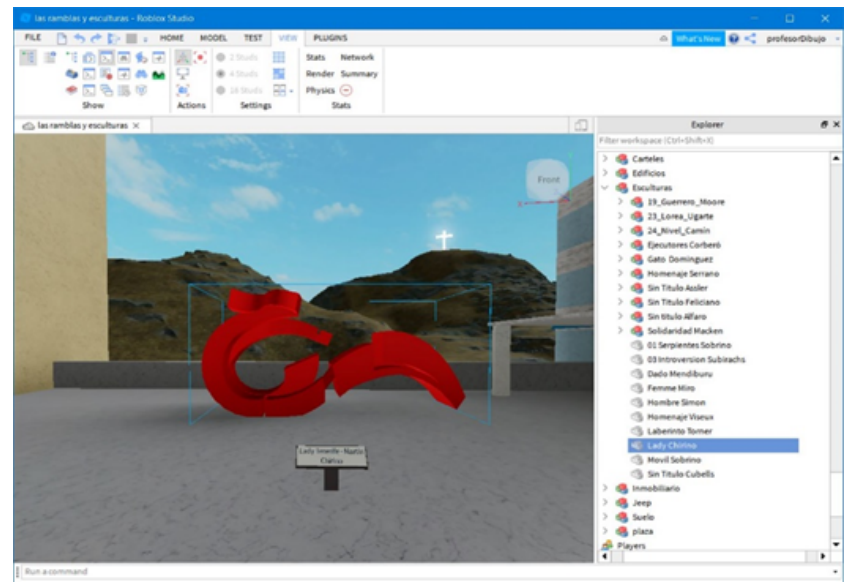

Fig. 1. Roblox Studio program view

\subsection{Use of video game engines in education}

The use of video game engines involves students in the creation of the content on which they work, making them participants in the construction of knowledge and not just as mere consumers [37]. The emergence of simple programming languages that allow the creation of video games makes them easier to use for those interested who do not have advanced knowledge in this area, and has therefore made it possible to incorporate the creation of video games in classrooms from primary school onwards [38].

Some researchers use video game creation to motivate pre-university students to become interested in computer science [39]. Others use video game creation as a creative way to introduce students to programming languages [40, 41, 42]. Kelleher and Pausch [43] use the Storytelling Alice programming environment to create computer-animated movies that inspire the interest of high school girls in learning to program.

Furthermore, video game engines are not used specifically to teach programming but to work on other content. Aldana-Avilés [44] used Scratch as a didactic intervention to teach the subject of English to second year students of secondary school with TDAH. In her project, she justified the use of this tool with the aim of developing appropriate methodologies to enhance concentration, self-control and creativity. Sarasa-Cabezuelo use Scratch as a tool that can be useful for teachers and students in the acquisition of second languages [45]. Martin Pérez [46] developed with Scratch activities for the subject of Music and Plastic and Visual Education of third year of secondary education. 
The activity consisted of students creating digital musical postcards to celebrate Christmas and to congratulate Father's Day. It justifies its use thanks to the possibilities provided by Scratch of implementing songs, making digital drawings and being able to program the animations of those drawings to the rhythm of music. Nogales and Valencia [47] developed an activity with a tool called eAdventure in order to teach a teaching unit for the subject of Natural Sciences through video games. They defend the potential of video games as an educational tool because they significantly increase participants' attention.

In this study, the Roblox Studio program was used to work on the city's sculptural heritage. The students learned to create and navigate in an interactive three-dimensional world in which they also included the sculptures of the city of Santa Cruz de Tenerife. The world they were asked to create could have any aspect and interactivity desired by the student, so the activity, in addition to the objective of getting to know the city's sculptural heritage, also aimed to empower the imagination of the participants.

\section{Creation of the world of Roblox}

Prior to the activity with students, an interactive world had been created with the Roblox Studio video game engine. In This way, an example was available to take a virtual tour of the sculptures, showing the possibilities of the program to the participants and verifying the functionality of Roblox. The virtual world is a reconstruction of reality, a 3D simulation of a physical space that represents part of the city of Santa Cruz de Tenerife, specifically the Rambla that crosses the entire city and the García Sanabria Park. In this area of the city are the sculptures of the I International Exhibition of Street Sculptures, a representative sculptural heritage of the city (Fig. 2). This world is available for virtual visit and play on any device in: https://www.roblox.com/ games/3155549868/las-ramblas-y-esculturas
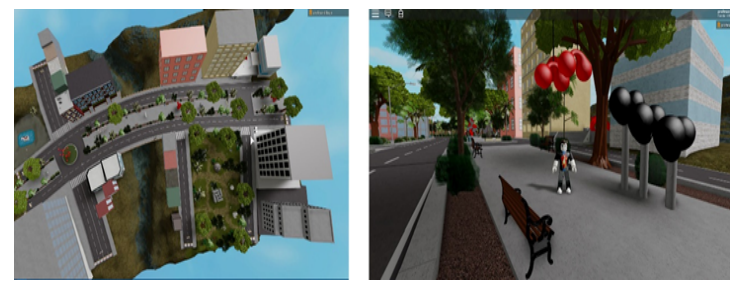

Fig. 2. Aerial perspective of the world and Las Ramblas with Sculptures

The virtual world has been created with objects (buildings, trees, streets, etc.) available for free in the Roblox Studio libraries. However, in order to incorporate the city sculptures into the project, a series of preparations had to be made for proper execution. In order to incorporate the sculptures into the Roblox Studio video game engine, the sculptures were first needed in three dimensions. The three-dimensional digitalization of the sculptures was previously carried out by Saorin et al. [48]. 
Roblox allows both the import of files with own formats (.rbxm) and generic formats that the video game industry usually works with (.obj, .fbx, .stl, etc.). The files of the digital sculptures of which this work is based are in the format of the modeling program Sketchup (.skp). Roblox does not allow the import of this type of files, so it was necessary to change the format of the sculptures to .fbx. The format change was done using the free program Autodesk FBX Converter (Fig. 3a).

Also, Roblox Studio has a limitation of 10.000 polygons when importing a 3D file. Some sculptures, especially those that were digitized using the photogrammetry process, exceeded this limit. The solution was to import these sculptures into a 3D modeling program that would allow the number of polygons to be lowered without deforming the object. With the Zbrush program, from the Pixologic company, the number of polygons in the sculptures was lowered thanks to a tool called Dynamesh. This tool works automatically and its function is to process the $3 \mathrm{D}$ object and recreate it with the amount of polygons that is configured (Fig. 3b).

The final format sculptures to work with in Roblox Studio were given to the students so that they could incorporate them into the virtual world that each one was going to design and are available at the following link: http://bit.ly/2uqRlzy.

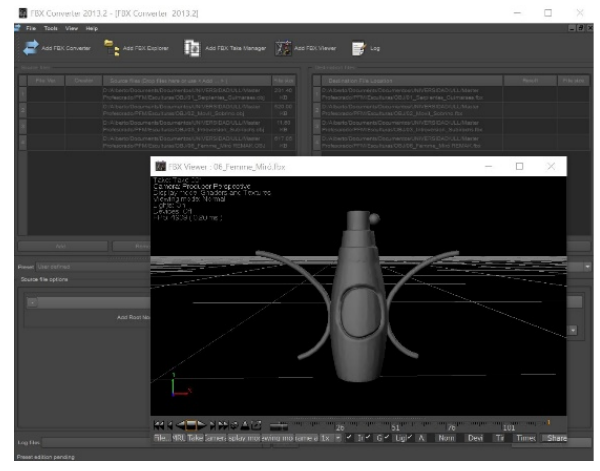

Fig. 3. (a)

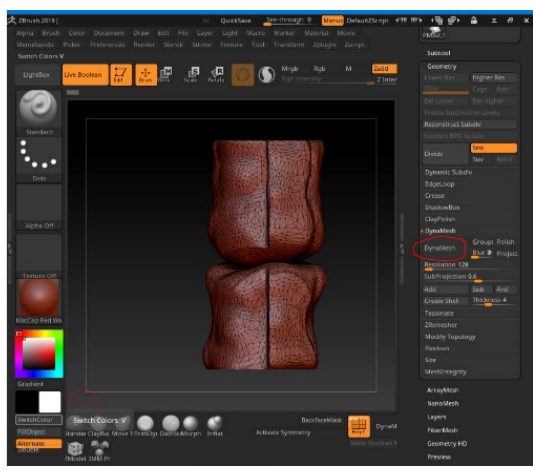

Fig. 3. (b)

Fig. 3. (a) Formatting using the free program called Autodesk FBX Converter.

Fig. 3. (b) Zbrush program to download the number of polygons of the sculptures using its tool called Dynamesh

\section{$4 \quad$ Materials and Methods}

\subsection{Participants}

The activity was carried out with 53 students on the subject of Plastic, Visual and Audiovisual Education of the MM Dominicas Vistabella School of Santa Cruz de 
Tenerife. The students were from the 4th year of secondary education and were divided into two groups. In the groups there were students of both sexes, between the ages of 14 and 17. Before the activity, the participants answered a questionnaire in order to determine their knowledge about video games. In this questionnaire, $80 \%$ of the participants stated that they played video games, but only $11 \%$ of them said that they used a video game engine (Unity, Unreal, Roblox Studio, etc.). Interestingly or Surprisingly $73 \%$ of the participants considered that previous knowledge of programming was required to make an interactive video game environment. Despite this, $72 \%$ indicated that they would like to do educational activities using video games and believed that designing a video game was closely related to the subject of plastic and visual expression.

\subsection{Measurement tools}

In order to validate the activity carried out, the participants filled out two questionnaires, one at the beginning of the activity to obtain data regarding the students' familiarization with video games, video game development, Roblox, and the sculptural heritage of Santa Cruz de Tenerife. Once the activity was finished, the participants filled in a second questionnaire (Likert scale 1-5) to obtain values about the use of Roblox as an educational tool in the school context, their perception about the design of video games and about the use of the sculptural heritage for learning.

\subsection{Hardware and software}

For the first part of the activity (virtual route through the model created by the teacher, which reproduces the streets of Santa Cruz de Tenerife and its sculptures), devices of the students were used, their own Smartphones, digital tablets and computers. This was possible because to navigate a 3D world of Roblox, it is only necessary to install the application and register with a user. For the second part of the activity, which consisted of creating the personalized world with the Roblox Studio video game engine, the participants formed groups of two to four people and used the students' computers. The sculptures in the appropriate format to be incorporated into the world were provided by the teacher through the virtual classroom of the school.

\subsection{Description of the activity}

The introduction of the sculptural heritage in the classroom through Roblox was divided into two activities.

Activity 1: Carry out the virtual route through the world Las Ramblas and Sculptures created by the research group as a test to familiarize the student with the use of the video game and observe each of the sculptures with their respective information posters.

Activity 2: The participants create their own virtual world in groups, which is free to design but which must also incorporate the sculptures as part of the environment's decoration. These sculptures must be accompanied by an informative poster with the name of the author and the title of the sculpture. 
The two activities were carried out in 6 sessions of one teaching hour. The first activity, with a duration of one session, consisted of registering with Roblox before being able to navigate the world of Las Ramblas and Sculptures. The purpose of this activity was to familiarize participants with the use of the video game and to observe each of the sculptures with their respective information posters, so that they would learn to recognize them. This activity could be carried out with the participants' own mobiles, tablets or computers, without the need for a specific classroom (Fig. 4).
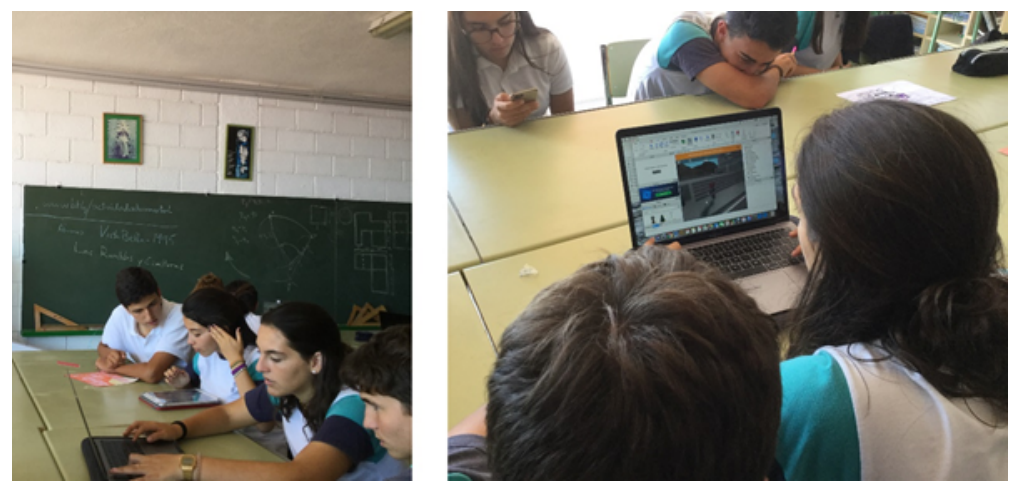

Fig. 4. Activity 1, students going through the world of the Ramblas and sculptures with their devices

For the second activity, during the remaining five sessions, students reinforced their knowledge about the sculptures while creating their own world. This exercise involved creative ingenuity, having to use the program's tools to design an original world in which to place the sculptures and being able to publish it online so that it could be explored by the rest of the class. This exercise required a computer room with internet access or in this case, each group of students had to bring a laptop from home.

After an introduction and explanation on how to download and install the Roblox Studio program, the participants observed an example by the teacher on how to handle the basic tools to create their own virtual environment. Then, in groups, the students proceeded to create their own worlds. To do so, they had to modify the terrain, incorporate objects from the program itself and import and place the sculptures from Santa Cruz de Tenerife belonging to the First International Street Sculpture Exhibition of 1973 provided by the teacher. The works had to be accompanied by a poster with the name of the work and the author. Finally, they were required to export the world in .rbxl format and publish it on the Roblox platform so that it can could be accessed by any user online.

\section{$5 \quad$ Results}

Each group of students was able to develop a personal world of free imagination with Roblox Studio including the sculptures provided by the teacher. In figure 5 we can see the variety of designs made by the participants. Each world is different from the 
others. We can observe desert spaces, ice worlds, more conventional cities with beaches and even pirates. In addition, the sculptural heritage of Santa Cruz de Tenerife has been incorporated, each work with its respective informative poster, in each of the creations.
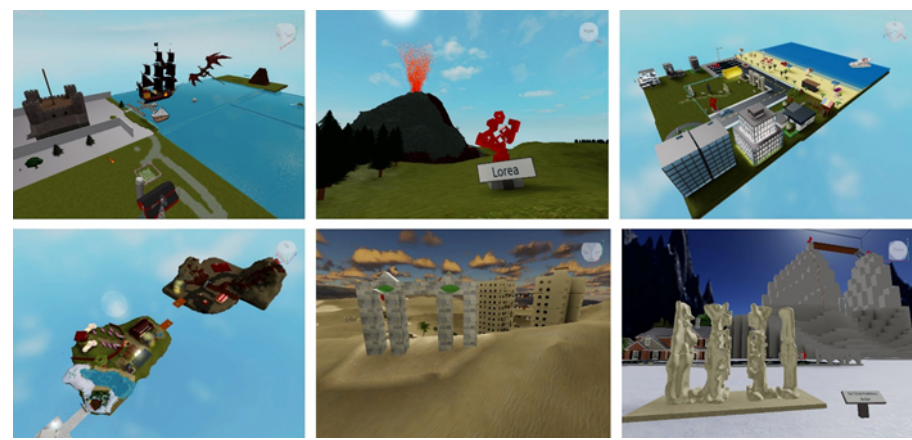

Fig. 5. Different results of worlds created by students

The table 1 shows the results of the questionnaire after the activity, measured on the Likert scale which is valued from 1 point (Nothing agreed) to 5 points (totally agreed).

Table 1. Results of the questionnaire after the activity

\begin{tabular}{|l|c|}
\hline \multicolumn{1}{|c|}{ Question } & Media (Est. Des.) \\
\hline After the activity I consider that I have the knowledge to make a simple video game & $3,49(1,14)$ \\
\hline I can create my own interactive world using the Roblox application & $3,82(1,07)$ \\
\hline I have found it easy to work with Roblox & $3,08(1,29)$ \\
\hline I would like to do more learning activities based on video games. & $2,98(1,52)$ \\
\hline Doing the activity has made me aware of the urban sculptures of Santa Cruz & $3,14(1,19)$ \\
\hline $\begin{array}{l}\text { Using a Roblox world seems to me to be useful for teaching - learning about sculptural } \\
\text { heritage }\end{array}$ & $3,22(1,19)$ \\
\hline \begin{tabular}{l} 
Learning with video games is a good complement to traditional materials. \\
\hline I believe that the use of Roblox improves motivation to study and learn in class.
\end{tabular} & $3,45(1,21)$ \\
\hline $\begin{array}{l}\text { I think that creating a virtual world is a suitable activity for the subject of Plastic and } \\
\text { Visual Education }\end{array}$ & $3,94(1,30)$ \\
\hline $\begin{array}{l}\text { I think that the subject of plastic and visual education should incorporate more digital } \\
\text { applications. }\end{array}$ & $3,27(1,27)$ \\
\hline
\end{tabular}

Cronbach's Alpha Coefficient of the questionnaire has been calculated, obtaining a result of 0.92 , so its reliability is considered excellent.

\section{Conclusion}

The first activity, which consisted of going around the previously created world, could be carried out without problems. All the students could access the virtual route and travel it using their digital devices, both mobile phones and tablets and computers. This facilitates the incorporation of the sculptural heritage in any educational space. Besides, this type of educational resource allows students with mobility problems to 
simulate virtual routes or walks that they would otherwise have great difficulty in taking. This first activity also served to familiarize them with the possibilities of Roblox as a video game platform. Therefore, it is considered a viable and well appreciated activity by students to incorporate the sculptural heritage in a classroom, using only the students' digital devices.

During the second activity, all groups were able to create an interactive world. Each group was able to experiment freely with the design possibilities of Roblox Studio resulting in very diverse and imaginative worlds. They were also able to incorporate the sculptures with their respective information posters into their creations. Thus, they worked on both, creativity and heritage, that are part of the curriculum of the plastic, visual and audiovisual education subject, while learning to create a video game.

After the activity, the participants, even though before the activity they did not consider themselves competent to make a video game, were able to create a simple video game (3.49 out of 5) by developing their own interactive world with Roblox Studio (3.82 out of 5). Therefore, this activity opens up fields of creation to students who previously did not think they were able to tackle this task. Consequently, it provides the opportunity to broaden the spectrum of careers they may want to study and facilitates the empowerment of participants in areas previously unknown to them. Most participants have found it easy to work with the program (3.08 out of 5) and useful to use an interactive world for teaching-learning about the sculptural heritage. They also considered this option a good addition to the use of traditional educational materials. They also felt that the use of Roblox motivated them to learn and study in class. With respect to the subject, they considered it to be an appropriate activity for plastic and visual expression (3.39 out of 5) and believed that more digital activities (3.27 out of 5) should be incorporated into secondary school studies.

In the future, the aim is to design the activity resulting in an exam to verify if students have in fact, learnt about the particular sculptural heritage they have worked on. Moreover, it is planned to measure to what extent the activity has improved the creativity or imagination of the participants.

\section{$7 \quad$ References}

[1] UNESCO, UNESCO. (2006). Textos Básicos de la Convención del Patrimonio Mundial 1972. Textos Básicos de la Convención del Patrimonio Mundial 1972, Paris: UNESCO, 2006. https://doi.org/10.33349/2002.38.1328

[2] EURYDICE, Educación artística y cultural en el contexto escolar europeo, Bruselas: Secretaría General Técnica, 2009.

[3] BOE, «Boletín Oficial del Estado, Disposiciones generales,» Ministerio de Educación, Cultura y Deportes, Madrid, 2015.

[4] M. Melgar y D. Donolo, «Salir del aula... Aprender de otros contextos: Patrimonio natural, museos e internet,» Revista Eureka sobre enseñanza y divulgación de las ciencias, p. 8, 2011. https://doi.org/10.25267/rev eureka ensen divulg cienc.2011.v8.i3.08

[5] J. A. Chamizo, «Una tipología de los modelos para la enseñanza de las ciencias,» Revista Eureka sobre enseñanza y divulgación de las ciencias, p. 7(1), 2010. https://doi.org/10.25 267/rev_eureka_ensen_divulg_cienc.2010.v7.i1.02 
[6] M. A. Rea-Ramirez, J. Clement y M. Núñez-Oviedo, «An instructional model derived from model construction and criticism theory,» de Model based learning and instruction in science, Netherlands, Springer, 2008, pp. 23-43. https://doi.org/10.1007/978-1-4020-6494-4_2

[7] H. J. Brown, Videogames and education, New York: Routledge, 2014.

[8] M. D. Griffiths, «The educational benefits of videogames,» Education and health, vol. 20, $\mathrm{n}^{\mathrm{o}} 3$, pp. 47-51, 2002.

[9] G. Kokkalia, A. Drigas, A. Economou, P. Roussos y S. Choli, «The Use of Serious Games in Preschool Education,» International Journal of Emerging Technologies in Learning (iJET), vol. 12, no 11, pp. 15-27, 2017. https://doi.org/10.3991/ijet.v12i11.6991

[10] M. Lewis y J. Jacobson, «Game engines,» Communications of the ACM, vol. 45, no 1, p. 27 , 2002.

[11] J. G. Sánchez, N. P. Zea, F. L. Gutiérrez y M. J. Cabrera, «De la Usabilidad a la Jugabilidad: Diseño de Videojuegos Centrado en el Jugador,» de IX Congreso Internacional Interacción, Albacete, 2008. https://doi.org/10.5377/entorno.v0i67.7488

[12] C. Meier, J. L. Saorin Pérez, J. de la Torre-Cantero, A. Bonnet de León y M. MelgarRamírez, «Construcción de un mundo virtual en Minecraft para el aprendizaje del patrimonio escultórico urbano,» RELATEC Revista Latinoamericana de Tecnología Educativa, vol. 15, n 3, pp. 83-97, 2016. https://doi.org/10.17398/1695-288x

[13] C. Meier, J. L. Saorin, J. de la Torre-Cantero y M. D. Díaz-Alemán, «Alternative Divulgation of the Local Sculptural Heritage: Construction of Paper Toys and Use of the Minecraft Video Game,» Sustainability; Sustainable Alternate Realities in Digital Heritage, vol. 10, n 4262, pp. 1-12, 2018. https://doi.org/10.3390/su10114262

[14] wepc, «WEPC,» 2211 2019. [En línea]. Available: https://www.wepc.com/news/videogame-statistics/.

[15] Aevi, «La industria del Videojuego en España. Anuario 2018,» Asociación española del videojuego, Madrid, 2018.

[16] Dev, Libro blanco del desarrollo español de videojuegos, Madrid: DEV, 2016.

[17] Q. Li, «Digital game building: learning in a participatory culture,» Educational research, pp. 427-443, 2010.

[18] J. Jeon, K. Kim y S. Jung, «A Study on the Game Programming Education Based on Educational Game Engine at School,» Journal of Education and Learning, vol. 1, nº 2, pp. 282287, 2012. https://doi.org/10.5539/jel.v1n2p282

[19] M. Swalwell, «The Early Micro User: Games writing, hardware hacking, and the will to mod,» de DiGRA Nordic 2012 Conference: Local and Global-Games in Culture and Society., Adelaide, 2012.

[20] M. B. Chen, «The implementation and evaluation of an easy-to-use mobile game development tool. In Engineering Innovation and Design,» de 7th International Conference on Innovation, Communication and Engineering (ICICE 2018), Hangzhou, China, 2019. https ://doi.org/10.1201/9780429019777-13

[21] Roblox, «Roblox Corporation,» 2411 2019. [En línea]. Available: https://corp.roblox.com/

[22] S. Perchy y S. Nishi, «Tecnologıas y Metodologias para la Producción, Diseno y Desarrollo de Videojuegos.,» 2013. [En línea]. Available: http://cic.javerianacali.edu.co/ ysperchy/ home/articles/game production.pdf.

[23] D. V. Fernandez y C. M. Angelina, Desarrollo de Videojuegos: Arquitectura del Motor de Videojuegos (Vol. 1), Ciudad Real: Bubok, 2011.

[24] H. Sun, «Design of Education Application based on Shiva 3D Platform,» International Journal of Emerging Technologies in Learning (iJET), vol. 12, n 4, pp. 200-207, 2017. https://doi.org/10.3991/ijet.v12i04.6685

[25] M. Á. Roque López, «Entendiendo la programación visual en el desarrollo de videojuegos,» Con A de Animación, n 9, pp. 92-100, 2019. https://doi.org/10.4995/caa.2019.11336

[26] F. Lundgren y R. Pearce-Authers, Lundgren, F., \& Pearce-Authers, R. (2013). CryENGINE Game Programming with C++, C\#, and Lua, Birmingham: Packt Publishing Ltd., 2013. 
[27] R. H. Creighton, Unity 3D game development by example: A Seat-of-your-pants manual for building fun, groovy little games quickly, Birmingham: Packt Publishing Ltd, 2010.

[28] P. V. Satheesh, Unreal Engine 4 Game Development Essentials, Birmingham: Packt Publishing Ltd., 2016.

[29] D. Klahr y S. M. Carver, «Cognitive objectives in a logo debugging curriculum: Instruction, learning, and transfer,» Cognitive Psychology, vol. 20, n 3, pp. 362 - 404, 1988. https ://doi.org/10.1016/0010-0285(88)90004-7

[30] R. Noss, «Constructing a conceptual framework for elementary algebra through logo programming,» programming. Educational Studies in Mathematics, vol. 17, n 4, pp. 335 - 357, 1986. https://doi.org/10.1007/bf00311324

[31] B. Broll, Collaborative Educational Environment Design for Accessible Distributed Computing, Vanderbilt University, 2018.

[32] J. Maloney, M. Resnick, N. Rusk, B. Silverman y E. Eastmond, «The scratch programming language and environment,» ACM Transactions on Computing Education (TOCE), vol. 10, $\mathrm{n}^{\circ}$ 4, pp. 1-15, 2010. https://doi.org/10.1145/1868358.1868363

[33] R. Sneyd, Stencyl Essentials, Birmingham: Packt Publishing Ltd., 2015.

[34] Aprendegamemaker, «Aprende Gamemaker,» 2911 2019. [En línea]. Available: https:// www.aprendegamemaker.com/programas-para-crear-videojuegos-gratis/.

[35] D. Jagneaux, The Ultimate Roblox Book: An Unofficial Guide, Massachusetts: Armas media, 2018.

[36] J. Cortés, «Retina, el Pais,» 168 2018. [En línea]. Available: https://retina.elpais.com/ retina/2018/08/16/talento/1534418035 383099.html.

[37] Y. B. Kafai, «Playing and Making Games for Learning: Instructionist and Constructionist Perspectives for Game Studies,» Games and Culture, vol. 1, n 1, pp. 36-40, 2006. https:// doi.org/10.1177/1555412005281767

[38] G. Chiazzese, G. Fulantelli, V. Pipitone y D. Taibi, «Engaging Primary School Children in Computational Thinking: Designing and Developing Videogames,» Education in the Knowledge Society (EKS), vol. 19, n 2, pp. 63-81, 2018. https://doi.org/10.14201/eks201 $\underline{81926381}$

[39] C. R. Hardnett, «Gaming for middle school students: building virtual worlds.,» de 3rd international conference on Game development in computer science education, Miami, Florida, 2008. https://doi.org/10.1145/1463673.1463678

[40] M. R. Davis, «Davis, M. R. (2013). Computer coding lessons expanding for k-12 students. Education Week.,» Education Week, vol. 6, nº 3, pp. 28-31, 2013.

[41] F. Kalelioğlu, «A new way of teaching programming skills to K-12 students: Code. org,» Computers in Human Behavior, vol. 52, pp. 200-210, 2015. https://doi.org/10.1016/j.chb. 2015.05.047

[42] G. A. Wright, P. Rich y K. R. Leatham, «How programming fits with technology education curriculum,» Technology and Engineering Teacher, vol. 71, nº 7, pp. 3-9, 2012.

[43] C. Kelleher y R. Pausch, «Using storytelling to motivate programming,» Communications of the ACM, 50(7), 58-64., vol. 50, n 7, pp. 58-64, 2007. https://doi.org/10.1145/1272516. 1272540

[44] D. L. Aldana Avilés, El lenguaje de programación Scratch como material didáctico motivador para la aplicación y evaluación de contenidos en el área de inglés para alumnos con diagnóstico de TDAH., Barcelona, 2015. https://doi.org/10.4995/var.2013.4326

[45] A. Sarasa-Cabezuelo, «Use of Scratch for the Teaching of Second Languages,» International Journal of Emerging Technologies in Learning (iJET), vol. 14, $\mathrm{n}^{\circ}$ 21, pp. 80-95, 2019. https://doi.org/10.3991/ijet.v14i21.11217

[46] A. I. Martín Pérez, Programando actividades musicales con Scratch en el aula de primaria., 2015.

[47] L. S. Nogales y L. P. S. Valencia, «Videojuegos como herramienta en Educación Primaria: Caso de estudio con eAdventure,» Revista Iberoamericana de Tecnología en Educación y 
Educación en Tecnología, vol. 18, pp. 101 - 112, 2016. https://doi.org/10.24215/18509959. 22.e04

[48] J. L. Saorin, C. Carbonell-Carrera, J. de la Torre-Cantero, C. Meier y D. Díaz-Alemán, «Three-Dimensional Interpretation of Sculptural Heritage with Digital and Tangible 3D Printed Replicas,» TOJET: The Turkish Online Journal of Educational Technology, vol. 16, $\mathrm{n}^{\circ}$ 4, pp. 161-169, 2017. https://doi.org/10.3390/su10114262

\section{Authors}

Cecile Meier is an Assistant Professor at University of La Laguna at the department of fine arts. Her research is specialized in the use of new technologies, videogames, interactive environments and digital fabrication in classroom for learning about art and heritage.

Jose Luis Saorín is senior professor in the area of engineering graphics at University of La Laguna and funder of the FabLab in Tenerife. His research is about videogames and interactive environments in education. He also research in the field of new technologies and digital fabrication.

Alejandro Bonnet de León is $\mathrm{PhD}$ graduated in the department of education at the University of La Laguna. His research interest lie in the fields of creating learning activities using three dimensional resources and Makerspaces in secondary education.

Alberto Guerrero Cobos is a graduate student from the master's degree in teaching in Secondary Education at University of La Laguna, currently working as coordinator/professor in 3D Animation, Games and Interactive Environments studies for Higher Education (HNC).

Article submitted 2020-06-24. Resubmitted 2020-07-21. Final acceptance 2020-07-22. Final version published as submitted by the authors. 